\title{
Intake of copper has no effect on cognition in patients with mild Alzheimer's disease: a pilot phase 2 clinical trial
}

\author{
Holger Kessler · Thomas A. Bayer · Daniela Bach · Thomas Schneider-Axmann · \\ Tillmann Supprian · Wolfgang Herrmann • Manfred Haber · Gerd Multhaup • \\ Peter Falkai · Frank-Gerald Pajonk
}

Received: 18 March 2008/Accepted: 5 June 2008/Published online: 28 June 2008

(C) The Author(s) 2008

\begin{abstract}
Disturbed copper $(\mathrm{Cu})$ homeostasis may be associated with the pathological processes in Alzheimer's disease $(\mathrm{AD})$. In the present report, we evaluated the efficacy of oral $\mathrm{Cu}$ supplementation in the treatment of $\mathrm{AD}$ in a prospective, randomized, double-blind, placebo-controlled phase 2 clinical trial in patients with mild AD for 12 months. Sixty-eight subjects were randomized. The
\end{abstract}

Holger Kessler, Thomas A. Bayer and Daniela Bach have contributed equally.

H. Kessler · D. Bach

Department of Psychiatry and Psychotherapy,

Saarland University Hospital, Homburg/Saar, Germany

T. A. Bayer $(\bowtie) \cdot$ T. Schneider-Axmann · P. Falkai

Division of Molecular Psychiatry, Department of Psychiatry

and Psychotherapy, University of Göttingen,

von-Siebold-Strasse 5, 37075 Göttingen, Germany

e-mail: tbayer@gwdg.de

\section{T. Supprian}

Department of Geriatric Psychiatry, Rheinische Kliniken

Düsseldorf, Dusseldorf, Germany

W. Herrmann

Central Laboratory, Department for Clinical Chemistry,

Saarland University Hospital, Homburg/Saar, Germany

\section{Haber}

Central Pharmacy, Saarland University Hospital,

Homburg/Saar, Germany

G. Multhaup

Institute for Chemistry and Biochemistry, Free University,

Berlin, Germany

F.-G. Pajonk

Center for Psychiatric and Psychotherapeutic Care and Rehabilitation, Dr. K. Fontheim's Hospital

for Mental Health, Liebenburg, Germany treatment was well-tolerated. There were however no significant differences in primary outcome measures (Alzheimer's Disease Assessment Scale, Cognitive subscale, Mini Mental Status Examination) between the verum [Cu-(II)-orotate-dihydrate; $8 \mathrm{mg} \mathrm{Cu}$ daily] and the placebo group. Despite a number of findings supporting the hypothesis of environmental $\mathrm{Cu}$ modulating $\mathrm{AD}$, our results demonstrate that oral $\mathrm{Cu}$ intake has neither a detrimental nor a promoting effect on the progression of $\mathrm{AD}$.

Keywords $\mathrm{Cu} \cdot$ Alzheimer $\cdot$ Clinical trial $\cdot$ ADAS-cog . MMSE

Abbreviations

AAS Atomic absorption spectroscopy

A $\beta \quad$ Amyloid beta peptide

AD Alzheimer's disease

ADAS-cog Alzheimer's disease assessment scale, cognitive subscale

ADRDA Alzheimer's disease and related disorders association

APP Amyloid precursor protein

CDT Clock drawing test

$\mathrm{Cu} \quad$ Copper

CuBD Copper binding domain

MMSE Mini mental status examination

NINCDS National Institute of Neurological and Communicative Disorders and Stroke

SOD-1 Superoxide dismutase-1

Zn Zinc

\section{Introduction}

Alzheimer's disease (AD) is a progressive neurodegenerative disease characterized by extracellular deposition of 
$\mathrm{A} \beta$ peptides in senile plaques and intracellular accumulation of hyperphosphorylated $\tau$ protein in neuronal cells as neurofibrillary tangles.

Potentially toxic $\mathrm{A} \beta$ peptides are generated from the copper-binding amyloid precursor protein (APP) by two independent proteolytic events (Bayer et al. 2001; Glenner and Wong 1984; Hesse et al. 1994; Kang et al. 1987). APP is actively involved in balancing $\mathrm{Cu}$ concentrations in cells. In APP-knock-out mice, $\mathrm{Cu}$ levels were found increased in cerebral cortex and liver (White et al. 1999), whereas overexpression of APP was reported to result in significantly reduced $\mathrm{Cu}$ levels in brain tissue of different APP transgenic mouse strains (Bayer et al. 2003; Phinney et al. 2003) and in mice overexpressing the $\mathrm{C}$-terminal fragment of APP (and enhanced A $\beta$ secretion) (Maynard et al. 2002).

The N-terminal $\mathrm{Cu}$ binding domain (CuBD-I) of APP shows structural homology to the $\mathrm{Cu}$ binding domain of $\mathrm{Cu}$ chaperons (Barnham et al. 2003) binding $\mathrm{Cu}$ with nanomolar affinity (Hesse et al. 1994). A secondary CuBD-II appears in $\mathrm{A} \beta$ after its release from APP (Atwood et al. 2000), and $\mathrm{Cu}$ application was reported to increase $\mathrm{A} \beta$ aggregation in vitro [reviewed in (Bush 2003)]. APP reduces $\mathrm{Cu}$ (II) to $\mathrm{Cu}$ (I), leading to oxidative modification of APP (Multhaup et al. 1996), which is facilitated through the protein surface localization of the binding site thus resembling so-called cytoplasmic $\mathrm{Cu}$ chaperones (Barnham et al. 2003).

In cell culture systems, $\mathrm{Cu}$ supplementation was found to stimulate the non-amyloidogenic APP pathway thereby suppressing the formation of $\beta$ amyloid (Borchardt et al. 1999). More recently, APP was shown in yeast cells to have a $\mathrm{Cu}$ efflux activity thereby explaining why APP overexpressing mice have a reduced $\mathrm{Cu}$ level in their brains (Bayer et al. 2003; Phinney et al. 2003; Treiber et al. 2004).

In the brain, APP transgenic mice have not only lower $\mathrm{Cu}$ levels but they also exhibit a reduced $\mathrm{Cu}, \mathrm{Zn}$ superoxide dismutase-1 (SOD-1) activity compared to wild-type mice. Dietary $\mathrm{Cu}$ supplementation in a transgenic mouse model for $\mathrm{AD}$ increased bioavailable brain $\mathrm{Cu}$ levels, restored SOD-1 activity, prevented premature death and decreased $\mathrm{A} \beta$ levels (Bayer et al. 2003). In Wilson's disease, a mutation of copper ATPase 7B leads to $\mathrm{Cu}$ accumulation in the liver and a threefold to fourfold higher $\mathrm{Cu}$ level in the brain. After crossbreeding of APP transgenic mice with socalled toxic milk mice having a defect in the copper ATPase 7B it was observed that APP-related lethality could be rescued. In addition, $\mathrm{A} \beta$ levels were significantly reduced due to the genetically upregulated $\mathrm{Cu}$ level (Phinney et al. 2003).

Earlier studies in animals have reported that elevated $\mathrm{Cu}$ is a risk factor for developing the $\mathrm{AD}$ related pathology.
Cherny et al. (2001) showed that clioquinol, a copper and zinc chelating agent, can remove $\beta$ amyloid plaque pathology. However, it was unclear how this effect worked, since the authors reported an increase of soluble $\mathrm{Cu}$ and $\mathrm{Zn}$ levels in the brain of treated mice. This apparently contradictory finding could be explained by the finding that clioquinol mediates $\mathrm{Cu}$ uptake by transporting $\mathrm{Cu}$ across cell membranes counteracting $\mathrm{Cu}$ efflux activities of APP (Treiber et al. 2004).

Normally, $\mathrm{Cu}$ contained in the food is taken up in the stomach and then absorbed in the small intestine. About $30-50 \%$ of the $\mathrm{Cu}$ is absorbed. $\mathrm{Cu}$ is distributed from the liver throughout the body and transported in the bloodstream bound to ceruloplasmin. The liver is the most important organ for $\mathrm{Cu}$ distribution and storage. $\mathrm{Cu}$ is excreted via the biliary system. Usually, $2 \mathrm{mg}$ of $\mathrm{Cu}$ per day are taken with food. Ingestion of as much as $10 \mathrm{mg}$ of $\mathrm{Cu}$ per day is considered to be safe. The clinical reference value for physiological $\mathrm{Cu}$ plasma concentrations is $65-165 \mu \mathrm{g} / \mathrm{dl}$ [reviewed in (Kessler et al. 2005)].

Since increased $\mathrm{Cu}$ levels reduced $\mathrm{A} \beta$ production in APP transgenic mouse models, we speculated that $\mathrm{Cu}$ intake stabilizes cognitive decline in $\mathrm{AD}$ patients. Thus, we treated $\mathrm{AD}$ patients with supplemental $\mathrm{Cu}$ and monitored the progression of the disease by recording the cognitive performance for 12 months using neuropsychological tests.

\section{Material and methods}

\section{Study population}

Criteria for participation in the study included written informed consent as well as caregiver consent, a diagnosis of probable AD by means of NINCDS-ADRDA criteria (McKhann et al. 1984), a Mini Mental Status Examination score $<25$, and receipt of a 5-10 mg dose of donepezil for at least 2 months. All patients continued to receive donepezil during the study. To be enrolled in the study patients had to be $50-80$ years of age and not able to bear children. Patients with severe and unstable somatic diseases and patients with present or known history of alcohol, drug or medication abuse were excluded. Patients taking drugs for coexistent diseases were included except those taking psychotropic drugs, "nootropics" or health food supplements. The trial has been approved by the appropriate ethics committee and has therefore been performed in accordance with the ethical standards laid down in the 1964 Declaration of Helsinki. All persons gave their informed consent prior to their inclusion in the study. 
Study design

The study had a monocenter, prospective, double-blind, placebo-controlled, parallel-group randomized design. Sixty-eight patients were recruited. Patients were randomly allocated either to placebo or to verum ( $\mathrm{Cu}$ orotate). The oral dosage of $\mathrm{Cu}$-(II)-orotate-dihydrate was $51.62 \mathrm{mg}$ (corresponding to $8 \mathrm{mg} \mathrm{Cu}$ ) once daily. To maintain blinding, capsules containing $\mathrm{Cu}$ orotate and placebo had identical shape and color. The duration of the study was 12 months. The study was registered at www.clinicaltrials.gov with the identification number NCT00608946.

\section{Study procedures}

Screening procedures consisted of a medical history, physical examination and psychometric tests. Blood was collected to determine the level of $\mathrm{Cu}$ and zinc by using atomic absorption spectroscopy (AAS). Furthermore, blood count included liver enzymes and anti-mitochondrial antibodies (for exclusion of cholestatic liver diseases). Atomic absorption spectroscopy: Blood samples were collected into metal-free tubes that contained lithium heparin as an anticoagulant. Concentrations of $\mathrm{Cu}$ were measured in lithiumheparin plasma samples, utilizing flame AAS (Perkin Elmer, AAnalyst 800). Samples were diluted with deionized water and the analysis was performed against standards prepared in glycerol to approximate the viscosity characteristics of the diluted samples. Standard atomic absorption conditions were utilized for $\mathrm{Cu}$ (air acetylene, wave length $324.8 \mathrm{~nm}$ ).

\section{Outcome measures}

The primary efficacy variables were the changes from the baseline score on the cognitive subscale of the Alzheimer's Disease Assessment Scale (ADAS-cog) and on the MMSE. Efficacy evaluations were performed at baseline and at month 3, 6, 9 and 12 .

\section{Therapeutic drug monitoring}

Plasma $\mathrm{Cu}$ levels were measured at every visit (at baseline and at month 3, 6, 9 and 12).

\section{Safety measures}

Standard adverse event reporting was conducted. Before baseline, the $\mathrm{Cu}$ content in drinking water at the patients' home was analyzed under standard conditions; concentration of $\mathrm{Cu}$ in drinking water must not exceed $2 \mathrm{mg} / \mathrm{l}$. For safety reasons, blood analyses (including especially plasma $\mathrm{Cu}$ levels and liver enzymes) were performed at week 1, 2, 3 and 4 after baseline and at month 3, 6, 9 and 12 .
Data analysis

Evidence of efficacy was indicated by a significant difference in change from baseline between treatment arms. For statistical analyses SPSS 14 was used. All tests were twotailed. Demographic variables, data on the course of the disease and clinical data at baseline of the patients that completed the examinations were compared between the verum and the placebo group with one-way analysis of variance (ANOVA). Chi-square test on independence was used to analyze, if the distribution of sex was different between the two groups. Dependent variables were the ADAS-cog total score and the MMSE score at baseline $\left(t_{0}\right)$ and at four following measurements with intervals of 3 months each $\left(t_{3}, t_{6}, t_{9}, t_{12}\right)$. Furthermore, plasma $\mathrm{Cu}$ levels at the beginning $\left(t_{0}\right)$ and at the end $\left(t_{12}\right)$ of the study were compared. Independent between-subject factor was treatment group (placebo, verum), within-subject factor was time of measurement. For ADAS-cog, MMSE and plasma copper the differences between the values at the end $\left(t_{12}\right)$ and at the beginning of the study $\left(t_{0}\right)$ were computed as measures for the changes over time. Pearson's product moment correlations between these differences and intervening variables age, disease duration, age at onset of the disease and duration of education were calculated, intending to analyze, if these variables show a significant influence on the changes of the dependent variables. ANOVA with between-subject factors treatment group and gender was use to analyze, if the changes were genderrelated. For the dependent variables Kolmogorov-Smirnov tests were used to test, if there were significant deviations from the normality assumption. The results of these preliminary statistics regulated the main analysis. The basic hypotheses were that the dependent variables ADAS-cog and MMSE change continuously over time and that these changes are different between the placebo and the verum group. The third hypothesis was that plasma copper level increases over time in the verum, but not in the placebo group. To analyze these hypotheses, the general linear model procedure was used to perform multivariate analyses of variance (MANOVA) with repeated measures design. Within-subject factor was time of measurement betweensubject factor was treatment group. Since there was no significant influence of the intervening variables sex, age, disease duration, age at onset of the disease and duration of education on the differences of the dependent variables between the values at the end and at the beginning of the study, no additional covariates or factors were entered to the model in the main analysis. In the repeated measures analyses MANOVA performed an orthonormal transformation of the dependent variables. The Mauchly test of sphericity was used to test the assumption that the covariance matrix of the transformed orthonormal variables was 




Fig. 1 Outline of flowchart of subjects studied. SAE serious adverse event

constant on the diagonal and zero off the diagonal. This was the case, if the values of the dependent variables show the same error and interaction effects at each measure time. If the sphericity assumption was violated, the GreenhouseGeisser epsilon correction was applied.

\section{Results}

Subject recruitment and demographics

The randomization of patients and their progress through the study is summarized in Fig. 1. A total of 120 patients were screened; 52 of these patients were excluded due to exclusion criteria. Altogether 68 subjects were randomized, with 33 patients receiving placebo and 35 patients receiving $\mathrm{Cu}$. There were no significant mean differences for age, disease duration, age at onset of the disease, education and clock drawing test at baseline between the verum and the placebo patients. The sex distribution was not significantly different between the two treatment groups (for details see Table 1). For the total verum and placebo group there were no significant correlations between the intervening variables age, disease duration, age at onset of the disease, duration of education and the changes over time for
ADAS $\operatorname{cog}\left(t_{12}-t_{0}\right)$, MMSE $\left(t_{12}-t_{0}\right)$ and plasma copper $\left(t_{12}-t_{0}\right)$. From ANOVA with factors group and gender there were no significant gender effects on the changes of the dependent variables over time. Therefore, no intervening variables had to be entered to the model in the main analysis. For all dependent variables, KolmogorovSmirnov tests did show no significant deviations from normality assumption.

Proof of concept

For the ADAS-cog score, an increase of the scores over time was observed in the placebo group ( $t_{12}$ vs. $t_{0}$ : $+15.5 \%)$ and in the verum group ( $t_{12}$ vs. $\left.t_{0}:+8.8 \%\right)$. From MANOVA with the repeated measures design there were significant effects of within-subject factor time $(d f=3.3$, $177.1 ; F=3.1 ; P=0.023$ ) and of between-subject factor treatment group $(d f=1,53 ; F=4.7 ; P=0.034)$ pointing out generally lower values in the verum group. However, there was no significant time $\times$ treatment group interaction $(d f=3.3,177.1 ; F=0.4 ; P=0.78)$ (Fig. 2a).

The MMSE score, a less sensitive measure of cognitive impairment, showed a similar pattern. There was a decrease over time in both treatment groups ( $t_{12}$ vs. $t_{0}$ : placebo: $-9.5 \%$, verum: $-10.5 \%$ ). The MANOVA 
Table 1 Demographic and clinical data at baseline of the patients that completed the study

\begin{tabular}{|c|c|c|c|c|c|}
\hline Sex (no. of males; no. of females) & $\begin{array}{l}\text { Placebo }(n=28) \\
m: 10 ; f: 18 \\
\text { Mean } \pm \text { SD }\end{array}$ & $\begin{array}{l}\text { Verum }(n=29) \\
m: 15 ; f: 14 \\
\text { Mean } \pm \text { SD }\end{array}$ & $\begin{array}{l}d f \\
1 \\
d f\end{array}$ & $\begin{array}{l}\chi^{2} \\
1.48 \\
F\end{array}$ & $\begin{array}{l}P \\
0.23 \\
P\end{array}$ \\
\hline Age (years) & $69.4 \pm 8.1$ & $69.6 \pm 6.6$ & 1,55 & 0.01 & 0.94 \\
\hline Disease duration (months) & $25.2 \pm 16.2$ & $34.0 \pm 31.2$ & 1,54 & 1.76 & 0.19 \\
\hline Age at onset (years) & $67.4 \pm 7.9$ & $66.6 \pm 6.1$ & 1,54 & 0.17 & 0.68 \\
\hline Education (years) & $10.6 \pm 1.9$ & $11.6 \pm 2.9$ & 1,54 & 2.28 & 0.14 \\
\hline CDT (scores) & $2.8 \pm 1.3$ & $2.8 \pm 1.2$ & 1,55 & 0.01 & 0.93 \\
\hline
\end{tabular}

$n$ Number of cases, $S D$ standard deviation, no. number, $F F$ statistics, $\chi^{2} \chi^{2}$ statistics, $P$ error probability for falsely rejecting the null hypothesis, that there are no mean differences between the treatment groups

repeated measures analysis resulted in significant effects of within-subject factor time $(d f=3.2,173.8 ; \quad F=9.5$; $P<0.0005)$. Effects of between-subject factor treatment group were not significant $(d f=1,54 ; \quad F=1.6$; $P=0.21$ ), and there was no significant interaction between time and treatment group $(d f=3.2,173.8 ; \quad F=0.2$; $P=0.88$ ) (Fig. 2b).

Altogether, cognitive abilities worsened progressively in $\mathrm{AD}$ patients receiving $\mathrm{Cu}$ as well as in those patients taking placebo. Differences between the two groups in the mean change from baseline scores were not statistically significant at any visit.

\section{Plasma levels of copper}

In both groups, mean absolute levels of $\mathrm{Cu}$ at baseline were within the age-related normative range. From MANOVA repeated measures analysis for plasma copper there were no significant mean differences for within-subject factor time ( $d f=1,50 ; F=1.7 ; P=0.20)$ and no significant effects for between-factor treatment group $(d f=1,50 ; F=1.1$; $P=0.29$ ), while the time $\times$ treatment group interaction was significant ( $d f=1,50 ; F=5.2 ; P=0.027$ ), as mean plasma $\mathrm{Cu}$ was decreased over time in the placebo group $\left(t_{12} \quad\right.$ vs. $t_{0}: \quad t_{12}$ mean $\pm \mathrm{SD}=98.5 \pm 17.7 \mu \mathrm{g} / \mathrm{dl}$ and $t_{0}$ mean $\left.\pm \mathrm{SD}=109 \pm 23.4 \mu \mathrm{g} / \mathrm{dl} ;-7.5 \%\right)$, but stabilized in the verum group ( $t_{12}$ vs. $t_{0}: t_{12}$ mean $\pm \mathrm{SD}=100.8 \pm$ $21.6 \mu \mathrm{g} / \mathrm{dl}$ and $t_{0}$ mean $\pm \mathrm{SD}=100.7 \pm 15.3 \mu \mathrm{g} / \mathrm{dl}$; $+2.3 \%$ ). No treatment effect was however observed on $\mathrm{Zn}$ and ceruloplasmin levels (not shown).

Safety results and analysis

Safety analysis was conducted on all data irrespective of the stage reached in the trial. In the placebo group, 28 patients $(84.5 \%)$ continued taking part until the end of the study, in the verum group 29 patients $(82.9 \%)$ completed treatment. From the Chi-square test on independence, the drop-out rate was not statistically different between the two groups $\left(\chi^{2}=0.05, \quad P=0.82\right)$. Six patients discontinued the

treatment in the $\mathrm{Cu}$ group: one withdrew consent, three due to adverse events, one due to non-compliance and one patient for other reasons. The mentioned drop-outs related to serious adverse events were hospitalizations due to intracranial hemorrhage (1 patient), diagnosis of non-Hodgkin

A


Fig. 2 Mean and standard deviation change in cognitive abilities. a Cognitive abilities assessed with ADAS-cog in $\mathrm{Cu}$ (verum) vs. placebo arms. b Cognitive abilities assessed with MMSE score in $\mathrm{Cu}$ (verum) vs. placebo arms 
lymphoma (1 patient) and suspected cerebral infarction (1 patient). None of the serious adverse events leading to discontinuation of the study was considered to be attributable to $\mathrm{Cu}$ supplementation. Five patients discontinued the participation in the placebo group. No serious adverse events leading to discontinuation were recorded in the placebo group. Three patients withdrew their consent, one failed to return and one discontinued for other reasons. The liver status and hematological characteristics of the patients was monitored at all visits. No significant changes were detected at any time as an effect of $\mathrm{Cu}$ treatment.

Altogether, the study medication was well-tolerated. There were no obvious overall trends or clinically relevant differences between the two groups in vital signs, physical examination, hematological characteristics or biochemical analyses.

\section{Discussion}

There is increasing evidence that the metalloproteins APP and $\mathrm{A} \beta$ are both involved in brain $\mathrm{Cu}$ homeostasis. Maynard et al. (2002) have shown that overexpression of the carboxy-terminal fragment of APP elicits significantly reduced $\mathrm{Cu}$ levels in transgenic mouse brain. In addition, overexpression of APP in three different lines of APP transgenic mice resulted in significantly reduced $\mathrm{Cu}$ levels (Bayer et al. 2003; Maynard et al. 2002; Phinney et al. 2003). This effect might be further enhanced by the reduced bioavailability of $\mathrm{Cu}$ due to the accumulation of high amounts of $\mathrm{Cu}$ in plaques (Lovell et al. 1998). The APP mediated $\mathrm{Cu}$ efflux activity observed in APP overexpressing living cells may also explain $\mathrm{Cu}$ deficiency and a subsequently reduced SOD-1 activity. Remarkably, the TxJ mutation of the toxic milk mouse (mutation in the Wilson's disease gene) with a genetically 1.5 -fold upregulated $\mathrm{Cu}$ level was associated with an increased survival of APP transgenic mice and lowered endogenous murine $\mathrm{A} \beta$ levels prior to detectable $\mathrm{A} \beta$ plaques formed by the human APP transgene. The CuATPase $7 \mathrm{~b}$ transporter is a Ptype ATPase associated with the trans Golgi network. These observations were the basis to hypothesize that restoring brain $\mathrm{Cu}$ homeostasis might have a beneficial influence on the progression of $\mathrm{AD}$.

In the present clinical trial, we demonstrate that oral intake of $\mathrm{Cu}$ orotate ( $8 \mathrm{mg} \mathrm{Cu}$ daily for 12 months) has no effect on cognitive abilities of AD patients and is neither detrimental nor beneficial. The treatment was generally well-tolerated. The plasma $\mathrm{Cu}$ levels declined in the placebo group during the 12 months-period. Such a decline was not observed in the $\mathrm{Cu}$-treated group. Although the placebo group had higher $\mathrm{Cu}$ levels as compared to the verum group at the beginning of the study this effect is of interest. However, this observation should be taken with caution, because the statistical significance is rather weak. The analysis of CSF $\mathrm{Cu}$ showed that the $\mathrm{Cu}$ levels were stabilized only in the $\mathrm{Cu}$-treated group. This observation indicates that oral $\mathrm{Cu}$ intake can modulate $\mathrm{CSF} \mathrm{Cu}$ levels and antagonizes the age-related increase of $\mathrm{Cu}$ levels hypothetically by activating the homeostatic system, i.e., balancing the uptake and excretion pathways $(\mathrm{H}$. Kessler et al., in preparation).

These observations are in good agreement with significantly lower levels of blood $\mathrm{Cu}$ in those $\mathrm{AD}$ patients, who fulfilled the criteria of $\mathrm{CSF}$ diagnosis for $\mathrm{AD}$, i.e., at least two of the three markers (A $\beta 42$, Tau, Phospho-Tau) were out of the reference range (Kessler et al. 2006). In addition, we demonstrated reduced $\mathrm{Cu}$ levels in blood in patients with higher ADAS-cog scores (making more mistakes in this neuropsychological test) (Pajonk et al. 2005), i.e., AD progression is associated with lower $\mathrm{Cu}$ levels in blood.

One animal study showed that treatment of 21-monthsold Tg2576 mice with clioquinol, a $\mathrm{Cu}-\mathrm{Zn}$ chelator, inhibited plaque formation and concomitantly increased soluble brain $\mathrm{Cu}$ and $\mathrm{Zn}$ levels (Cherny et al. 2001). This increase of $\mathrm{Cu}$ - and $\mathrm{Zn}$-ions might either be attributed to an inefficiency of the chelator with its known weak affinities for $\mathrm{Zn}(\mathrm{K} 1=7.0)$ and for $\mathrm{Cu}(\mathrm{K} 1=8.9)$ or even more likely, due to a facilitated uptake in brain of clioquinol- $\mathrm{Cu}$ complexes. The latter hypothesis has been experimentally confirmed in vitro (Treiber et al. 2004). Moreover, lowered insoluble $\mathrm{A} \beta$ levels (by $49 \%$ ) and increased soluble $\mathrm{A} \beta$ levels (by 50\%) were accompanied with elevated $\mathrm{Cu}$ levels (and Zn).

When $\mathrm{AD}$ patients were treated with clioquinol, the placebo group deteriorated faster than the clioquinol group suggesting a beneficial effect upon clioquinol treatment (Ritchie et al. 2003). This could be due to clioquinol mediating $\mathrm{Cu}$ uptake into the cell or the metal-proteinattenuating-compunds properties. In APP transgenic mice $\mathrm{Cu}$ supplementation abrogated this clioquinol effect and rescued premature death (Schafer et al. 2007).

Postmortem $\mathrm{Cu}$ levels in CNS of $\mathrm{AD}$ patients were found to be decreased (Deibel et al. 1996) or unchanged (Loeffler et al. 1996). Controversial results have also been published on the level of $\mathrm{Cu}$ in plasma, plasma and brain in $\mathrm{AD}$ patients. Plasma $\mathrm{Cu}$ levels being within the normal range in $\mathrm{AD}$ patients is in good agreement with an earlier study (Jeandel et al. 1989). However, other studies suggest that elevated $\mathrm{Cu}$ levels are a risk factor for $\mathrm{AD}$ (Squitti et al. 2002, 2003, 2004).

Short-term high $\mathrm{Cu}$ intake has been reported not to affect $\mathrm{Cu}$ status or functions related to $\mathrm{Cu}$ status, only longterm high $\mathrm{Cu}$ intake can result in increases in some parameters in young men (Turnlund et al. 2004). Our study is in good agreement with this report adding further 
evidence that long-term intake of $\mathrm{Cu}$ stabilizes $\mathrm{Cu}$ levels in plasma.

The present clinical trial demonstrates that (1) long-term oral intake of $8 \mathrm{mg} \mathrm{Cu}$ can be excluded as a risk factor for AD. (2) Long-term oral intake of $\mathrm{Cu}$ is well-tolerated by AD patients. (3) $\mathrm{Cu}$ intake has no effect on the progression of AD.

Acknowledgments The excellent technical help of Patricia Nagel, Katrin Rubly, Stephanie Schaefer, Oliver Wirths, Karl-Heinz Hoffmann and Irene Witzmann is gratefully acknowledged. Financial support was provided by the HOMFOR program of the Saarland University Medical Faculty and the International Copper Association. This work has been supported in part by the International Copper Association (to Thomas A. Bayer) and Saarland University (HOMFOR program to Frank-Gerald Pajonk). The authors report no conflicts of interest. We have full control of all primary data and agree to allow the journal to review their data if requested.

Open Access This article is distributed under the terms of the Creative Commons Attribution Noncommercial License which permits any noncommercial use, distribution, and reproduction in any medium, provided the original author(s) and source are credited.

\section{References}

Atwood CS, Scarpa RC, Huang X, Moir RD et al (2000) Characterization of copper interactions with alzheimer amyloid beta peptides: identification of an attomolar-affinity copper binding site on amyloid beta1-42. J Neurochem 75(3):1219-1233

Barnham KJ, McKinstry WJ, Multhaup G, Galatis D et al (2003) Structure of the Alzheimer's disease amyloid precursor protein copper binding domain. A regulator of neuronal copper homeostasis. J Biol Chem 278(19):17401-17407

Bayer TA, Wirths O, Majtenyi K, Hartmann T et al (2001) Key factors in Alzheimer's disease: beta-amyloid precursor protein processing, metabolism and intraneuronal transport. Brain Pathol 11(1):1-11

Bayer TA, Schäfer S, Simons A, Kemmling A et al (2003) Dietary Cu stabilizes brain SOD-1 activity and reduces amyoid $\mathrm{A} \beta$ production in APP23 transgenic mice. Proc Natl Acad Sci USA 100(24):14187-14192

Borchardt T, Camakaris J, Cappai R, Masters CL et al (1999) Copper inhibits beta-amyloid production and stimulates the non-amyloidogenic pathway of amyloid-precursor-protein secretion. Biochem J 344(Pt 2):461-467

Bush AI (2003) The metallobiology of Alzheimer's disease. Trends Neurosci 26(4):207-214

Cherny RA, Atwood CS, Xilinas ME, Gray DN et al (2001) Treatment with a copper-zinc chelator markedly and rapidly inhibits beta-amyloid accumulation in Alzheimer's disease transgenic mice. Neuron 30(3):665-676

Deibel MA, Ehmann WD, Markesbery WR (1996) Copper, iron, and zinc imbalances in severely degenerated brain regions in Alzheimer's disease: possible relation to oxidative stress. J Neurol Sci 143(1-2):137-142

Glenner GG, Wong CW (1984) Alzheimer's disease: Initial report of the purification and characterization of a novel cerebrovascular amyloid protein. Biochem Biophys Res Commun 120:885-890

Hesse L, Beher D, Masters CL, Multhaup G (1994) The beta A4 amyloid precursor protein binding to copper. FEBS Lett 349(1):109-116
Jeandel C, Nicolas MB, Dubois F, Nabet-Belleville F et al (1989) Lipid peroxidation and free radical scavengers in Alzheimer's disease. Gerontology 35(5-6):275-282

Kang J, Lemaire HG, Unterbeck A, Salbaum JM et al (1987) The precursor of Alzheimer's disease amyloid A4 protein resembles a cell-surface receptor. Nature 325:733-736

Kessler H, Pajonk FG, Supprian T, Falkai P et al (2005) The role of copper in the pathophysiology of Alzheimer's disease. Nervenarzt 76(5):581-585

Kessler H, Pajonk FG, Meisser P, Schneider-Axmann T et al (2006) Cerebrospinal fluid diagnostic markers correlate with lower plasma copper and ceruloplasmin in patients with Alzheimer's disease. J Neural Transm 113(11):1763-1769

Loeffler DA, LeWitt PA, Juneau PL, Sima AA et al (1996) Increased regional brain concentrations of ceruloplasmin in neurodegenerative disorders. Brain Res 738(2):265-274

Lovell MA, Robertson JD, Teesdale WJ, Campbell JL et al (1998) Copper, iron and zinc in Alzheimer's disease senile plaques. J Neurol Sci 158(1):47-52

Maynard CJ, Cappai R, Volitakis I, Cherny RA et al (2002) Overexpression of Alzheimer's disease amyloid-beta opposes the age-dependent elevations of brain copper and iron. J Biol Chem 277(47):44670-44676

McKhann G, Drachman D, Folstein M, Katzman R et al (1984) Clinical diagnosis of Alzheimer's disease: report of the NINCDS-ADRDA Work Group under the auspices of Department of Health and Human Services Task Force on Alzheimer's Disease. Neurology 34(7):939-944

Multhaup G, Schlicksupp A, Hesse L, Beher D et al (1996) The amyloid precursor protein of Alzheimer's disease in the reduction of copper(II) to copper(I). Science 271(5254):1406-1409

Pajonk F, Kessler H, Supprian T, Hamzei P et al (2005) Cognitive decline correlates with low plasma concentrations of copper in patients with mild to moderate Alzheimer's disease. J Alzheimers Dis 8(1):23-27

Phinney AL, Drisaldi B, Lugowski S, Schmidt $S$ et al (2003) In vivo reduction of amyloid $A B$ by a mutant copper transporter. Proc Natl Acad Sci USA 100(24):14193-14198

Ritchie CW, Bush AI, Mackinnon A, Macfarlane S et al (2003) Metalprotein attenuation with iodochlorhydroxyquin (clioquinol) targeting Abeta amyloid deposition and toxicity in Alzheimer disease: a pilot phase 2 clinical trial. Arch Neurol 60(12):1685-1691

Schafer S, Pajonk FG, Multhaup G, Bayer TA (2007) Copper and clioquinol treatment in young APP transgenic and wild-type mice: effects on life expectancy, body weight, and metal-ion levels. J Mol Med 85(4):405-413

Squitti R, Lupoi D, Pasqualetti P, Dal Forno G et al (2002) Elevation of serum copper levels in Alzheimer's disease. Neurology 59(8):1153-1161

Squitti R, Pasqualetti P, Cassetta E, Dal Forno G et al (2003) Elevation of serum copper levels discriminates Alzheimer's disease from vascular dementia. Neurology 60(12):2013-2014

Squitti R, Cassetta E, Dal Forno G, Lupoi D et al (2004) Copper perturbation in 2 monozygotic twins discordant for degree of cognitive impairment. Arch Neurol 61(5):738-743

Treiber C, Simons A, Strauss M, Hafner M et al (2004) Clioquinol mediates copper uptake and counteracts copper efflux activities of the amyloid precursor protein of Alzheimer's disease. J Biol Chem 279(50):51958-51964

Turnlund JR, Jacob RA, Keen CL, Strain JJ et al (2004) Long-term high copper intake: effects on indexes of copper status, antioxidant status, and immune function in young men. Am J Clin Nutr 79(6):1037-1044

White AR, Reyes R, Mercer JF, Camakaris J et al (1999) Copper levels are increased in the cerebral cortex and liver of APP and APLP2 knockout mice. Brain Res 842(2):439-444 